\title{
EDITORIAL
}

\section{Four more years!}

\section{Introduction}

Meeting in Lisbon, Portugal on May 3rd 2006, the board of directors of the International Psychogeriatric Association (IPA) endorsed the recommendation of its executive that I be reappointed for a further (and final under the terms of the IPA constitution) four year term to serve as editor of International Psychogeriatrics from 1 January 2007 to 31 December 2010. I accepted this offer with delight, so unless I get fired for misconduct, drop dead or resign early, readers and authors are stuck with me until the end of the decade. As we strive to further develop and improve the journal this is an appropriate moment to reflect on what has changed since I took over at the start of 2003, report how the journal stands at present and indicate what developments may lie ahead.

\section{The journal at the start of $\mathbf{2 0 0 3}$}

Robin Eastwood and his predecessor editors bequeathed to my care a well established peer-reviewed journal. Circulation to IPA members and libraries was close to 2000 which meant that the journal had better penetration than some of its key competitors. Nothing that has been accomplished subsequently could have been done without the tremendous work of those who edited the journal before me, but in January 2003 the journal did face some challenges. It was not yet published online, its agreement with its founder publisher was due to expire at the end of the year, it was not appearing on time, submissions were not flowing in at a rate which was sufficient to sustain four 128 page issues per year and it did not have a Science Citation Index (SCI) Impact Factor (IF), though an application to receive one had been made the previous year.

\section{Innovations and developments since January 2003}

\section{Impact factor (IF)}

Journal IFs are measured by a private company (Thomson Scientific, formerly Institute for Scientific Information) and published in June each year. They are the result of a calculation which adds up the number of papers (excluding such ephemera as conference abstracts, editorials, letters, news items and book reviews) published in a journal in the two previous years (the denominator) and then divides that figure into the number of times any articles published in 
the journal in the previous two years have been cited in peer-reviewed journals (including the journal whose IF is being calculated itself) in the current year (the numerator), thus giving a figure for the number of times an "average" article from a particular journal's previous two years' worth of issues has been cited during the year under consideration. (see Garfield, 2005 for a full account). In other words, the 2005 IF for International Psychogeriatrics was calculated by counting citations during 2005 of articles published in 2003 and 2004. Some universities use the IFs of journals in which an individual academic has published as a crude way of measuring the importance of that person's research, so publishing in high impact journals is a goal to which many authors aspire. This editorial will not discuss the many problems inherent in using journal IFs to judge academic performance, as these have been extensively rehearsed elsewhere (e.g. Seglen, 1997). Suffice it to say that although there is a lot wrong with IFs as a crude measure of a journal's worth, we are lumbered with them for now, and a journal with a high IF is more likely to attract quality submissions (and thus maintain or raise its IF further) than one with a low IF or no IF listing at all.

The decision whether or not to calculate and publish the IF of a particular journal is made by Thomson Scientific and although journals may lobby for recognition, inclusion is at Thomson's discretion. In the years prior to 2003 several IPA members pointed out that unless International Psychogeriatrics were to acquire an IF they would not submit articles for publication, because to do so would disadvantage them in their academic careers. In 2002 our former publisher, Springer Publishing of New York asked for the journal to be accorded the same courtesy as its competitors such as the International fournal of Geriatric Psychiatric and the American fournal of Geriatric Psychiatry and to have an IF calculated and listed. This request came to fruition in June 2003 when our 2002 IF was reported as 1.118 , somewhat lower than that of our two main competitors, but much better than having no IF at all. We were delighted when this rose to 1.577 in 2003, but disappointed when it fell to 0.918 in 2004. In 2005 it rose again to 1.215 . Why did we slip back in 2004 and what can be done to sustain an improved IF?

The journal's 2003 IF reflected 153 citations of 97 articles published in 2001 and 2002, while the 2004 IF was calculated on the basis of 101 citations of 111 articles from 2002 and 2003. As a quick glance at table 1 will reveal, both IFs must include articles in supplements as we did not publish anything close to 97 or 111 original research articles and review articles in our regular issues in $2001 / 2002$ or $2002 / 3$. Having discussed and considered the fall in some detail over time, the editorial team think that one reason that it occurred was because SCI counted articles published in our 2003 "Vascular Burden of the Brain" supplement, which for some reason was not been notified to all of the major indexing services until September 2005 when Leonardo Pantoni brought it to 
our attention that the supplement was not listed in Medline, and was thus hard to access and therefore unlikely to be cited widely. In addition the fact that most of its 48 articles were brief and often highly specialized (i.e. there were a lot of them and perhaps only a few were highly citable), may have played a role in depressing the citation rate.

With a rising number of submissions and a high rejection rate (see table 2) the quality of our published articles should be improving, and when taken together with our policy of publishing at least one review article (these tend to be highly cited) per issue our IF ought to rise over time. It might improve further if our self citation rate (the percentage of references articles in the journal to other articles previously published in International Psychogeriatrics), which is unusually low at $3.5 \%$, were to rise even a little bit.

\section{Style of manuscripts and information to be included therein}

In 2003 International Psychogeriatrics moved into line with many other leading journals in requiring authors of original research articles to include a structured abstract at the head of their papers. Structured abstracts are easier for readers to comprehend and provide information in a more user-friendly manner than unstructured ones.

In order that readers and authors planning to submit articles to the journal may have some idea of how efficiently our review process is running, we then introduced the practice of listing at the foot of the first page of each review and original research article the dates on which it was received at the editorial office, returned to the authors for revision, received at the editorial office in its final revised version and then the date on which it was accepted for publication. Thus those reading the journal can see whether or not our review process is rapid or slow, and how long authors have to wait for publication of an accepted article. Recently we have also added the date on which an article was first published online as a "forthcoming article".

Many authors have relationships with one or more pharmaceutical companies (without which some research would never be performed) and it is not uncommon for other links and interests to have at least the potential to influence what authors say in papers and how they interpret and present the results of their research. As outlined in our "Instructions to contributors" available online as a PDF at www.journals.cambridge.org/jid_IPG and published every year in the first issue of each volume of the journal, now we require that every submitted paper carry a conflict of interest declaration detailing any relationships or interests which might have the potential to influence an author, which again brings us into line with most major biomedical journals (Ames, 2004).

The bestowal of "gift" or unjustified authorship has been a cause for concern in some quarters. Requiring all papers to carry a description of which author did 
what in the conduct of a piece of research and the preparation of a manuscript will not get rid of that problem altogether, but there are grounds to believe that it may impact upon the practice to at least some extent, and it does allow readers to draw their own conclusions about who should get most of the credit for a published piece of work. At any rate, we have made the inclusion of a "description of authors' roles" statement mandatory for all review and original research articles submitted to the journal.

Our first "for debate article" (Ames et al., 2005) excited considerable interest and is followed by a second in this issue. Two further such articles are close to completion and at least one more is in the pipeline. Suggestions for other debate topics (especially if accompanied by recommendations of individuals capable of and willing to undertake the authorship of conflicting arguments) will be received with interest at ipaj-ed@unimelb.edu.au.

Nobody seems to have missed the annual index which we axed in 2004 . Modern electronic searching has rendered such indices redundant and getting rid of it saved us enough pages to publish one extra article every year.

Our most recent innovation was announced and justified in the last issue (Ames, 2006). In requiring all papers reporting randomized clinical trials submitted from the end of 2006 to have been previously registered in a clinical trials registry we are following the stated policy of the International Council of Medical Journal Editors and once more are bringing ourselves into line with the practices followed by prestigious organs such as the New England fournal of Medicine and the Lancet.

\section{Electronic publishing and Cambridge University Press (CUP)}

When I took over as editor the IPA had already decided to invite proposals to publish the journal in 2004 and beyond, and one of my first duties was to assist in the selection of one of the four publishers who had submitted bids. Cambridge University press (CUP) was the successful bidder, and one factor in their success was their commitment to publish not only new issues online from the first issue they would produce, but to make available online all the journal's back issues (whose copyright is owned by IPA). Without doubt this overdue innovation has been useful. Articles are more likely to be cited if electronically available and IPA has at last found itself in a position where it can offer affordable membership subscriptions to individuals in the developing world as "electronic only packages" which cost far less to deliver than traditional "hard copy" subscriptions.

Another advantage of electronic publishing is that once articles have been accepted and typeset, they can be published online well in advance of the specific journal issue in which they are slated to appear. This is of particular benefit when there is something of a backlog of accepted articles awaiting assignment 
to specific issues (see below) as the article counts as published from the date on which it first appears online. We aim to have no more than a two month delay from acceptance to online publication, and if readers examine the last few papers to appear on the "Forthcoming Articles" section of our website they will see that we are now achieving his goal more often than not.

CUP were quick to address the problem of late publication which has been an intermittent problem for the journal throughout its history. Since CUP took over as publisher our four annual issues due out in March, June, September and December have been published electronically on the following dates: April 2nd 2004, June 22nd 2004, September 24 2004, December 21 2004, April 5 2005, June 29 2005, September 14 2005, December 6 2005, April 4 2006, and May 30 2006. The hard copies usually have been mailed two weeks later. Our aim is to publish each issue online two weeks before the start of the month in which it is scheduled to appear (i.e. 14 February for the March issue) and to mail issues no later than the first day of the month of publication. With plenty of material already published online we expect to be hitting our electronic publication date targets in a consistent manner by the end of 2006.

We have been well served in our relationship with CUP by the commitment and enthusiasm of their journal managers Conrad Guettler, Gavin Swanson and Jamie Hutchins, our production editors Gwenda Edwards and Sue Tuck, the copyeditors Judith Sylph and Gill Mautner and the staff in charge of journal promotion and reprints Charlene Gibbons and Rebecca Curtis. Therefore I am very pleased to announce that IPA has decided to extend for a further two years our current publishing relationship beyond the end of our current contract which expires at the end of 2006.

\section{Getting bigger and being efficient}

Table 1 gives some idea of how the journal has grown since it made its debut in two annual issues in 1989. From a starting point of 210 pages in its first year the journal increased its publication frequency to four issues annually in 1995 and then peaked in size at 696 pages in its regular issues (not counting supplements) in 1996, fell back somewhat to 446 pages in both 2002 (the year prior to my appointment) and 2003, before publishing a record 724 pages in 2005. This year we are on track to publish 766 pages in our four regular issues. In 2005 we published a record 39 original research articles. The number of book reviews published has burgeoned since Robin Eastwood's innovative appointment of the journal's first book review editor ten years ago, and in 2005 we printed more book reviews (34) than ever before. Letters too have become an important facet of the journal and we will publish more in 2006 than in any other year. 


\begin{tabular}{|c|c|c|c|c|c|c|c|c|c|c|c|c|c|c|c|c|c|c|c|c|c|c|c|c|c|c|c|c|}
\hline 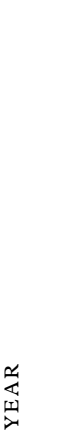 & 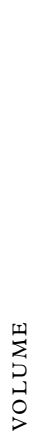 & $\begin{array}{l}\infty \\
\text { ஸు } \\
D \\
\infty \\
\infty \\
\sim\end{array}$ & $\begin{array}{l}\infty \\
\text { 至 } \\
0 \\
\mathbb{4}\end{array}$ & 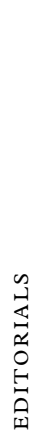 & 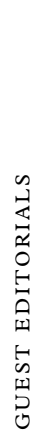 & 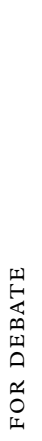 & 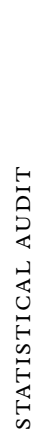 & 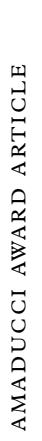 & 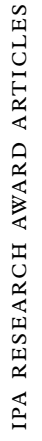 & 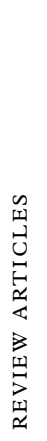 & 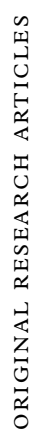 & 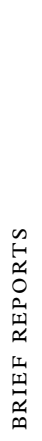 & 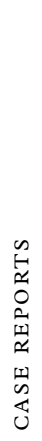 & 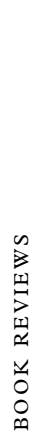 & 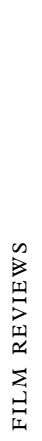 & 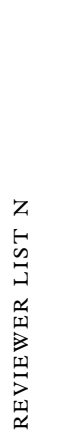 & $\begin{array}{l}\stackrel{a}{a} \\
x \\
x \\
\dot{I} \\
\hat{a} \\
z\end{array}$ & 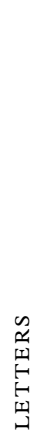 & 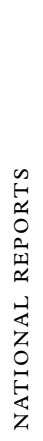 & 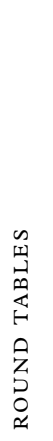 & $\begin{array}{l}n \\
z \\
o \\
\vec{Z} \\
a \\
\vdots \\
0\end{array}$ & 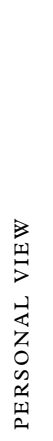 & 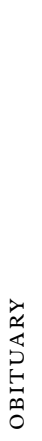 & 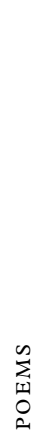 & $\stackrel{N}{\stackrel{N}{\sigma}}$ & 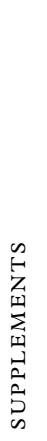 & 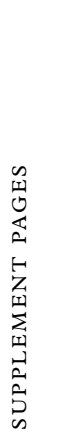 & 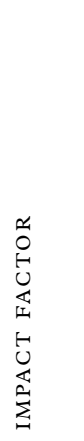 \\
\hline 1989 & 1 & 2 & 210 & 2 & 0 & 0 & 0 & 0 & 0 & 1 & 14 & 0 & 0 & 2 & 0 & - & 0 & 0 & 3 & 0 & 0 & 0 & 0 & 0 & 0 & 0 & 0 & - \\
\hline 1990 & 2 & 2 & 184 & 2 & 1 & 0 & 0 & 0 & 2 & 2 & 6 & 0 & 0 & 4 & 0 & - & 0 & 0 & 3 & 0 & 0 & 0 & 0 & 0 & 2 & 0 & 0 & - \\
\hline 1991 & 3 & 2 & 414 & 1 & 1 & 0 & 0 & 0 & 0 & 20 & 13 & 0 & 0 & 4 & 0 & - & 0 & 0 & 1 & 0 & 0 & 0 & 0 & 0 & 2 & 1 & 84 & - \\
\hline 1992 & 4 & 2 & 272 & 2 & 0 & 0 & 0 & 0 & $0^{1}$ & 2 & 17 & 0 & 0 & 3 & 0 & - & 0 & 0 & 2 & 0 & 0 & 0 & 0 & 0 & 1 & 2 & 312 & - \\
\hline 1993 & 5 & 2 & 222 & 2 & 0 & 0 & 0 & 0 & 0 & 1 & 14 & 0 & 1 & 3 & 0 & - & 0 & 0 & 2 & 0 & 0 & 0 & 0 & 0 & 0 & 0 & 0 & - \\
\hline 1994 & 6 & 2 & 232 & 2 & 0 & 0 & 0 & 0 & 3 & 4 & 9 & 0 & 0 & 9 & 0 & - & 0 & 0 & 1 & 0 & 0 & 0 & 0 & 0 & 0 & 0 & 0 & - \\
\hline 1995 & 7 & 4 & 584 & 1 & 3 & 0 & 0 & 0 & 0 & 9 & 38 & 0 & 0 & 0 & 0 & 59 & 12 & 0 & 0 & 0 & 0 & 0 & 0 & 0 & 0 & 1 & 142 & - \\
\hline 1996 & 8 & 4 & 696 & 3 & 1 & 0 & 0 & 0 & 3 & 7 & 33 & 0 & 0 & 0 & 0 & 67 & 20 & 0 & 0 & 5 & 0 & 0 & 0 & 0 & 0 & 3 & 552 & - \\
\hline 1997 & 9 & 4 & 496 & 4 & 5 & 0 & 0 & 0 & 3 & 4 & 25 & 1 & 3 & 4 & 0 & 76 & 14 & 0 & 0 & 0 & 0 & 0 & 0 & 0 & 0 & 1 & 328 & - \\
\hline 1998 & 10 & 4 & 450 & 3 & 3 & 0 & 0 & 0 & 0 & 2 & 31 & 1 & 0 & 10 & 0 & 77 & 9 & 0 & 0 & 0 & 0 & 0 & 0 & 0 & 0 & 0 & 0 & - \\
\hline 1999 & 11 & 4 & 472 & 0 & 4 & 0 & 0 & 0 & 0 & 1 & 31 & 1 & 0 & 11 & 0 & 96 & 13 & 0 & 0 & 0 & 6 & 0 & 1 & 0 & 0 & 1 & 208 & - \\
\hline 2000 & 12 & 4 & 576 & 2 & 4 & 0 & 0 & 0 & 3 & 0 & 38 & 0 & 0 & 10 & 0 & 92 & 11 & 0 & 0 & 0 & 0 & 0 & 0 & 1 & 0 & 1 & 424 & - \\
\hline 2001 & 13 & 4 & 570 & 3 & 3 & 0 & 0 & 0 & 3 & 0 & 34 & 0 & 0 & 12 & 0 & 86 & 11 & 0 & 0 & 0 & 0 & 1 & 0 & 2 & 0 & 2 & 562 & - \\
\hline 2002 & 14 & 4 & 446 & 0 & 4 & 0 & 0 & 0 & 0 & 0 & 31 & 0 & 0 & 26 & 0 & 102 & 14 & 0 & 0 & 0 & 0 & 0 & 0 & 0 & 0 & 1 & 128 & 1.118 \\
\hline 2003 & 15 & 4 & 446 & 4 & 5 & 0 & 0 & 1 & 0 & 0 & 26 & 0 & 0 & 25 & 0 & 95 & 13 & 0 & 0 & 0 & 0 & 0 & 0 & 0 & 0 & 2 & 690 & 1.577 \\
\hline 2004 & 16 & 4 & 506 & 1 & 4 & 0 & 1 & 1 & 3 & 5 & 18 & 0 & 0 & 28 & 0 & 154 & $-^{2}$ & 6 & 0 & 0 & 0 & 0 & 0 & 0 & 0 & 0 & 0 & 0.918 \\
\hline 2005 & 17 & 4 & 724 & 0 & 4 & 1 & 0 & 0 & 0 & 5 & 39 & 0 & 2 & 34 & 1 & -3 & - & 5 & 0 & 0 & 0 & 0 & 0 & 0 & 0 & 2 & 647 & 1.215 \\
\hline $2006^{4}$ & 18 & 2 & 382 & 2 & 0 & 0 & 0 & 0 & 3 & 2 & 17 & 0 & 3 & 18 & 0 & 197 & - & 12 & 0 & 0 & 0 & 0 & 0 & 0 & 0 & 0 & 0 & - \\
\hline
\end{tabular}

${ }^{1}$ IPA research award papers published in supplement (1992).

2 Index abolished 2004.

${ }^{3}$ Reviewer list moved from December to March issue (2004-2006).

${ }^{4} 1$ st January-30th June data only for 2006. 
The publication of supplements has been more erratic over the years. These days we publish the biennial Congress abstracts as a supplement to the journal. Other supplements are produced if funding can be obtained from an outside source (usually a pharmaceutical company) and if the proposed scientific content is approved by a core group comprising editor, deputy editor, chair of the publications committee and any members of the editorial panel we ask to assist in the process. Some supplements (e.g. the 2003 "Vascular Burden of the Brain" supplement) have been the result of consensus conferences (usually organized by IPA) while others (e.g. last year's excellent "Uncommon Dementias" supplement) stem from the enthusiasm of a group of researchers.

I have been unable to obtain precise details of submission rates prior to 2003, but since my Melbourne office took over the management of new submissions in April 2003, there has been a steady annual growth in submission rates from 64 in the last 9 months of 2003 (equivalent to an annual rate of 85 papers per annum) to 114 in 2004, 120 in 2005 and 64 to 30 June 2006 (equivalent to 128 papers per annum) (see table 2). The low page totals in 2002-2003 probably reflected low submission rates in 2001-2002 which may have been due, in part, to our lack of an IF. Some 2002 and 2003 issues were only 88 pages long. With our steady and increasing flow of manuscripts we now have trouble working out how we are going to fit everything in rather than having to wonder how we will fill the available space.

The fact that International Psychogeriatrics is experiencing increasing popularity as a destination for submitted manuscripts suggests that we must be doing something right by our authors, but this situation brings with it its own challenges. Although we now publish accepted papers rapidly online as "Forthcoming Articles", we do not want to keep authors waiting for more than 12 months before their papers appear in a regular issue of the journal. To expand the number of pages per annum costs money and the journal was a loss maker for IPA from its foundation until it first made a small surplus in 2004, but we intend to increase the number of pages we publish each year as soon as IPA can afford to do so.

Table 2 shows how quickly we deal with submitted articles and return them to authors. Rapid turnaround is a courtesy much valued by contributors. My target is that no paper should spend longer than 90 days in the initial review process. We failed $7.8 \%$ of authors in this regard in $2003,5.3 \%$ in $2004,5.0 \%$ in 2005 and $4.1 \%$ in 2006 to the end of June, but although we do not always meet this goal (occasionally because a reviewer lets us down, but more often because two reviewers disagree in their assessment of a paper necessitating a third tie-breaking review, or because at least one reviewer indicates that the paper needs further 
Table 2. International Psychogeriatrics - submission statistics 2003-2006 ("Papers" category includes review articles, Amaducci and IPA Research awards articles and all other original research articles, but excludes editorials, guest editorials, for debate articles and book reviews, all of which are specially commissioned not spontaneously submitted)

\begin{tabular}{|c|c|c|c|c|c|c|c|c|c|c|c|}
\hline & & & & & & & PAPERS & & & & \\
\hline & & & & & & & RETURNED & & & & \\
\hline & & & & & & & FOR & & & & \\
\hline & & & & & & & REVISION & & & & \\
\hline & & & & & & & BUT NO & & & & \\
\hline & & & & & & & REVISED & & PAPERS & & \\
\hline & MIN & MAX & & & & & VERSION & & STILL & & \\
\hline & RESPONSE & RESPONSE & & & PAPERS & PAPERS & YET & PAPERS & UNDER & LETTERS & LETTERS \\
\hline YEAR & (DAYS) & (DAYS) & MEDIAN & MEAN & RECD & ACCEPTED & RECEIVED & REJECTED & REVIEW & RECEIVED & ACCEPTED \\
\hline $2003^{1}$ & 7 & 140 & 49 & 55 & 64 & $28(44 \%)$ & $4(6 \%)$ & $32(50 \%)$ & 0 & 1 & 1 \\
\hline 2004 & 17 & 151 & 42 & 50 & 114 & $41(36 \%)$ & $2(2 \%)$ & $71(62 \%)$ & 0 & 7 & 6 \\
\hline 2005 & 9 & 100 & 57 & 46 & 120 & $57(48 \%)$ & $5(4 \%)$ & $58(48 \%)$ & 0 & 15 & 15 \\
\hline $2006^{2}$ & 0 & 105 & 58 & 43 & 64 & $12(19 \%)$ & $12(19 \%)$ & $25(39 \%)$ & $15(23 \%)$ & 9 & 9 \\
\hline
\end{tabular}

19 months data only 1st April-31st December 2003

26 months data only: 1st January-30th June 2006 
assessment by an expert in statistics) we try hard to keep authors informed about the progress and status of their paper at an early date if unavoidable delays occur.

\section{Future prospects}

As the burgeoning worldwide increase in both absolute numbers of elderly people and their percentage of the population continues in future decades, International Psychogeriatrics aspires to be the leading journal concerned with the mental health of old people. We want reading the journal to be an indispensable requirement for all who are active in the field. No other old age psychiatry journal combines our global reach and interests with our affordability and accessibility. We have not reached a position of pre-eminence yet, but with the support of our parent organization IPA, the only international body dedicated to all areas of mental health of the elderly (not just dementia), a committed publisher with strong international links, and an editorial panel which contains a judicious mix of sage experience and youthful enthusiasm, we have the potential to achieve that goal. You, our readers can assist us and serve your own best interests by submitting your best work, citing our papers when appropriate, reviewing when asked to do so, joining, rejoining and encouraging others to join IPA. In return we promise to review your work promptly and fairly with the help of experienced and capable reviewers from our database of over 400 experts in all aspects of psychogeriatrics. The aging of the global population is a necessary prelude to a world with a stable number of humans who have a markedly lighter impact on the fragile ecology of our only home than has hitherto been the case. The challenges to be addressed as the population ages are considerable but manageable. In that process International Psychogeriatrics aims to be of practical help. Please support us.

DAVID AMES

Editor-in-Chief International Psychogeriatrics

Professor of Psychiatry of Old Age, University of Melbourne, St George's Hospital, Kew, Victoria, Australia

Email: ipaj-ed@unimelb.edu.au

\section{References}

Ames, D. (2004). International Psychogeriatrics goes online. International Psychogeriatrics 16, 1-2. doi:10.1017/S1041610204000018.

Ames, D., Ballard, C., Cream, J., Shah, A., Suh, G-H. and McKeith, I. (2005). For debate: should novel antipsychotics ever be used to treat the behavioural and psychological symptoms of dementia (BPSD). International Psychogeriatrics 17, 3-29. doi:10.1017:S104161020500102X. 
Ames, D. (2006). Registration of clinical trials submitted for publication in International Psychogeriatrics. International Psychogeriatrics 18, 191-193. doi: $10.1017 / \mathrm{S} 1041610206003413$

Chibnall, J. (2000). Some basic issues for clinicians concerning things statistical. International Psychogeriatrics 12, 3-7.

Chibnall, J. (2004). Statistical audit of original research articles published in International Psychogeriatrics for the year 2003. International Psychogeriatrics 16, 389-396. doi: $10.1017 /$ S10416102040000821

Garfield, E. (2005). The agony and the ecstasy - the history and meaning of the journal impact factor. http://garfield.library.upenn.edu/papers/jifchicago2005.pdf

Seglen, P. O. (1997). Why the impact factor of journals should not be used for evaluating research. $B M \mathcal{F} 314,497$. 